\title{
Optimization of COVID-19 face mask waste fibers and silica fume as a balanced mechanical ameliorator of fat clay using response surface methodology
}

\author{
Zia ur Rehman ${ }^{1}$ (1). Usama Khalid ${ }^{2}$
}

Received: 13 July 2021 / Accepted: 2 October 2021 / Published online: 16 October 2021

(c) The Author(s), under exclusive licence to Springer-Verlag GmbH Germany, part of Springer Nature 2021

\begin{abstract}
The balanced amelioration of mechanical characteristics of fat clay with an additive refers to the attainment of high strength without compromising ductility, which is unattainable by solitary usage of a cementing additive. For this purpose, an amalgamated binary admixture (ABA) is proposed by assimilating shredded face mask (FM) waste, which is posing serious environmental concerns these days, with a cementitious waste material, i.e., silica fume (SF). However, for such ABA, the optimization of mix design is desirable because an excessive amount of one component could disturb the required balance. To address this issue, response surface methodology (RSM) is used in the current study, which is a strong technique used during the process of production to develop, improve, and optimize product inputs. Several experiments are designed and conducted to evaluate mechanical responses, i.e., unconfined compressive strength $\left(q_{u}\right)$, brittleness index $\left(I_{B}\right)$, deformability index $\left(I_{D}\right)$, and California bearing ratio $(C B R)$ value, of treated fat clay by varying mix designs of ABA. Based on the test results, mathematical models are developed which are found to be statistically valid to predict the subjected responses using SF and FM as inputs. Afterward, an optimized mix design is determined by integrating developed models with a desirability function model and setting maximization of strength and ductility as the optimization goals. An ABA having 7.9\% SF and $1.2 \% \mathrm{FM}$ is observed to provide the highest strength and ductility for multiple applications, i.e., road and buildings, with desirability factor close to unity; responses of which are also validated by performing tests. Furthermore, analysis of cleaning aspect shows that the use of optimized $\mathrm{ABA}$ in place of cement for subgrade improvement of $1 \mathrm{~km}$ two-lane road could avoid $\mathrm{CO}_{2}$ emission of around $79,032 \mathrm{~kg}$ of $\mathrm{C}$, save $42,720 \mathrm{kWh}$ and $1174.8 \mathrm{GJ}$ of electrical and thermal energy, respectively, and clean $43 \mathrm{Mg}$ of FM waste; however, astute protocols of COVID-19 FM waste handling and disinfection are needed to be established and followed.
\end{abstract}

Keywords COVID-19 face mask waste $\cdot$ Waste and pollution reduction $\cdot$ Ductility $\cdot$ Mechanical properties $\cdot$ Response surface methodology

\section{Nomenclatures}

3D Three-dimensional

A Represent the SF in Eqs. (8)-(11)

Responsible editor: Philippe Garrigues

Zia ur Rehman

ziaur.rehman@uettaxila.edu.pk; engr.zrehman@gmail.com

Usama Khalid

engr.usamakhalid@yahoo.co.uk

1 Department of Civil Engineering, University of Engineering and Technology (UET), Taxila 47080, Pakistan

2 National Institute of Transportation (NIT), National University of Sciences and Technology (NUST), Risalpur 23200, Pakistan
ABA Amalgamated binary admixture

ANOVA Analysis of variance

ASTM American Society for Testing and Materials

$B \quad$ Represent the FM in Eqs. (8)-(11)

CBR California bearing ratio

$D \quad$ Global desirability

$I_{B} \quad$ Brittleness index

$I_{D} \quad$ Deformability index

FCCCD Face-centered central composite design

FM Face mask

$n \quad$ Number of observations

$p \quad$ Intercept of observations

PF Polypropylene fiber

PRESS Prediction error sum of squares

$q_{u} \quad$ Unconfined compressive strength 


$\begin{array}{ll}q_{r} & \text { Residual compressive strength } \\ R^{2} & \text { Coefficient of determination } \\ \text { RSM } & \text { Response surface methodology } \\ \text { SSM } & \text { Mean sum of squares } \\ \text { SSR } & \text { Residual sum of squares } \\ \text { SST } & \text { Total sum of square } \\ \text { USCS } & \text { Unified soil classification system } \\ \text { SF } & \text { Silica fume } \\ w_{\text {opt }} & \text { Optimum moisture content } \\ \varepsilon_{a} & \text { Axial strain } \\ \varepsilon_{f} & \text { Strain at failure } \\ \gamma_{d m a x} & \text { Maximum dry unit weight } \\ \widehat{Y} & \text { Predicted response value } \\ \sigma^{2} & \text { Mean square of residual } \\ \operatorname{Max}_{i} & \text { Maximization value } \\ \operatorname{Min}_{i} & \text { Minimization value } \\ T_{i} & \text { Target value }\end{array}$

\section{Introduction}

Conservation of natural resources and multidisciplinary utilization of waste by-products as the substitute material under the concept of the circular economy has gained substantial attention in the last few decades. This approach is necessary for promoting productive environmental management, sustainable development, and economic growth. Recently, after getting hit by the COVID-19 pandemic, the realization of a clean ecosystem and need for the multidisciplinary proposals for environmental management is higher than ever, since the environmentalists have warned that the continuous COVID19 pandemic could spur the ongoing environmental issues (Boroujeni et al. 2021; Van-Fan et al. 2021). Among different environment-related issues caused by this pandemic, the impact of COVID-19-related waste generation is of utmost concern (Sharma et al. 2020). Personal protective equipment (PPE)-related wastes like rubber gloves, face masks (FMs), and hand sanitary bottles lying on streets and floating on and below the water bodies have become a common observation of these days due to their extensive usage, as reported in various literature (Das et al. 2020; Dharmaraj et al. 2021), glimpsing the scale of this waste problem. As a pandemic control measure supported by various studies (Feng et al. 2020; Matuschek et al. 2020; Worby and Chang 2020), the World Health Organization (WHO) has introduced guidelines for the public to wear a surgical FM as a protective measure. As a result, 700 million FMs are consumed every day in Africa alone, and this number is 2.2 billion/day in Asia alone, involving large manufacturing and consequent expenditures (Nzediegwu and Cheng et al. 2020; Sangkham 2020; Wu et al. 2020). This has also considerably escalated the volume of FM waste, making waste management rather challenging around the world (Hantoko et al. 2021; Liao et al. 2021). The main plastic-type material used in surgical FMs is polypropylene which takes many years to disintegrate in traditional waste disposal; on the other hand, when such FM waste ends up in the water bodies, it results in microplastics and breaches our ecosystems by ending up in our sustenance sources (Sarkodie and Owusu 2020; De-la-Torre and Aragaw 2021; Dharmaraj et al. 2021). Thus, viable and productive FM waste management schemes are required, not only from an economic perspective but also to minimize the adverse effect of this pandemic on our ecosystem (Haleem et al. 2020; Ibn-Mohammed et al. 2020; Singh et al. 2020a, b).

Fat clay is a commonly encountered earthen material by civil engineers all over the world, regarded as problematic soil in terms of its mechanical properties (Abbey et al. 2021). The civil engineering structure built over or using such soil remains prone to failure. From an economic point of view, utilization of fat clay with a cost-effective treatment scheme is desirable to limit the use of borrowed material for the construction in the fact clay-rich areas. Different traditional cementitious materials, i.e., cement and lime, are commonly used as ameliorators for the mechanical properties of the fat clay (Eyo and Abbey 2021). However, to promote natural resource conservation and environmental burden reduction, the use of the aforementioned material is needed to be restricted by incorporating possible substitute waste materials (Xu et al. 2020). In this regard, the use of silica fume (SF) in cementitious stabilization of fat clay could be a promising dimension since SF is widely incorporated as a cementitious material in the concrete (Al-Soudany 2018; Phanikumar 2020; Singh et al. 2020a, b). The amelioration of mechanical properties of fat clay with cementitious agents is reliable in terms of strength (Tiwari et al. 2020). However, the ductility of stabilized fat clay with the cementitious additives deteriorates considerably due to increase in the hardened gel in the soil specimen (Phanikumar 2020; Singh et al. $2020 \mathrm{a}, \mathrm{b})$. Treatment of fat clay with such additives may not be desirable under seismic loading or where sudden failures are to be avoided. Balanced amelioration of the mechanical properties of fat clay requires not only an increase in strength but the catering of ductility. In literature, different researchers have employed plastic polypropylene fiber (PF) reinforcement to enhance the ductility of the cemented soil since fibers could reinforce the tension cracks under the loading. However, less increase in the strength is observed for the PF as a lone stabilizer as compared to the cementitious stabilizers. Excess use of PFs could also deteriorate the strength characteristics of fat clay (Singh et al. 2020a, b). Balanced amelioration of the mechanical properties of fat clay is achieved by using an amalgamated binary admixture (ABA) having both cementitious agent and PF in few studies (Elkhebu et al. 2019; ur Rehman and Khalid 2021). However, for such ABA, the optimized selection of mix design 
of cementitious agent and PFs remains in question because an excessive amount of one could cause adverse impacts (Yilmaz 2015; Elkhebu et al. 2019).

The top and bottom faces of the FM are made of nonwoven fabric, while polypropylene is used as its middle layer. Thus, the material of FM urges to reuse its waste as a fiber reinforcement agent in fat clay stabilization. The use of astutely handled FM waste in the construction industry could address the waste management issues of the pandemic in an effective manner. The authors proposed that a balanced amelioration of mechanical properties of fat clay can be achieved by integrating FM fibers and SF in an optimized mix design ratio (ur Rehman and Khalid 2021). Further, to determine an optimized mix design of ABA, the response surface methodology (RSM) is used based on series of experiments in this study. RSM is a strong technique used during the process of production to develop, improve, and optimize product inputs; it involves manifold statistical and mathematical computations. However, this technique is not widely used in soil stabilization as per literature (Güllü and Fedakar, 2017). The current study for the first time employs the RSM to determine the optimized mix design of SF and FM to propose a reasonable FM waste-based ABA for the balanced amelioration of the mechanical characteristics of fat clay. The conclusions offered in terms of optimum stabilizer mix design (FM and SF) ratio are believed to be beneficial for the practitioners and could pave the way for practical usage of FM waste in fat clay stabilization.

\section{Materials and methods}

\section{Material characterization}

Table 1 manifests the engineering properties of soil selected for amelioration in this study. The liquid limit, plasticity index, and clay content of selected soil were around 83, 52, and $66 \%$, respectively. The soil was classified as fat clay

Table 1 Characteristics of selected soil

\begin{tabular}{ll}
\hline Characteristics & Selected soil \\
\hline Liquid limit, $w_{L}(\%)$ & 83 \\
Plastic limit, $w_{p}(\%)$ & 31 \\
Plasticity index, $I_{p}(\%)$ & 52 \\
Clay content $(\%)$ & 66 \\
Silt content $(\%)$ & 33 \\
Sand content $(\%)$ & 11 \\
Maximum dry unit weight, $\gamma_{\text {dmax }}\left(\mathrm{kN} / \mathrm{m}^{3}\right)$ & 15.9 \\
Optimum water content, $w_{\text {opt }}(\%)$ & 24.5 \\
Unconfined compression strength, $q_{u}(\mathrm{kPa})$ & 153.4 \\
CBR-value $(\%)$ & 3.1 \\
USCS & $\mathrm{CH}$ \\
\hline
\end{tabular}

$(\mathrm{CH})$ as per the Unified Soil Classification System (USCS). The unconfined compressive strength $\left(q_{u}\right)$ and California bearing ratio $(C B R)$ values of the soil were around $153 \mathrm{kPa}$ and $3.1 \%$, respectively. Table 2 presents the chemical analysis results of the soil. The subjected soil contained $\mathrm{SiO}_{2}$ as the predominant element followed by $\mathrm{Al}_{2} \mathrm{O}_{3}$ and Cao. Moreover, the ABA used in this study was a mixture of SF and FM. The chemical analysis of SF showed that SF used in this study was predominantly composed of $\mathrm{SiO}_{2}$ (around $96 \%$ ) followed by $\mathrm{Cao}$ and $\mathrm{Na}_{2} \mathrm{O}$ (Table 2). Moreover, FM was used in a shredded form excluding nose strip and ear band materials. Due to COVID-19 restriction, unused FMs were utilized in the current study. However, actual FM waste could be used after proper disinfection. Literature survey reveals different disinfection methods of used FM including prolonged storage, usage of disinfectant solutions, ultraviolet germicidal irradiation, dry heating, and dry microwave heating exposure (Doan 2020; Haghani et al. 2020; Hamzavi et al. 2020; Lowe et al. 2020; Suman et al. 2020; Meyers et al. 2021). Any of these methods could be adopted with intense care; however, their effect on the FM fibers must be taken into consideration before using disinfected FM in soil stabilization. Recommending any disinfection method is beyond the scope of the current study.

\section{RSM description}

The following major steps were subsequently performed in RSM: (i) design of experiments, (ii) performance of experiments, (iii) mathematical modeling and statistical evaluation, (iv) optimization of mix design based on required responses, and (v) validation of predicted results of optimized solution based on experimental results. The first two steps define the methodology to acquire a database, and the next steps provide results of response surface analysis (RSA) (Mazumder et al. 2021). In the design of experiments, different mix designs were determined to conduct various tests as

Table 2 Chemical characteristics of soil and silica fume

\begin{tabular}{lll}
\hline Compound name & $\begin{array}{l}\text { Soil } \\
\%\end{array}$ & $\begin{array}{l}\text { Silica fume } \\
\%\end{array}$ \\
\hline Calcium oxide $(\mathrm{CaO})$ & 8 & 1.5 \\
Silicon dioxide $\left(\mathrm{SiO}_{2}\right)$ & 46.8 & 92 \\
Aluminum oxide $\left(\mathrm{Al}_{2} \mathrm{O}_{3}\right)$ & 14.6 & 0.6 \\
Ferric oxide $\left(\mathrm{Fe}_{2} \mathrm{O}_{3}\right)$ & 6.2 & 0.5 \\
Magnesium oxide $(\mathrm{MgO})$ & 2.8 & 0.41 \\
Loss of ignition & 14.2 & 3.1 \\
Potassium oxide $\left(\mathrm{K}_{2} \mathrm{O}\right)$ & - & 0.5 \\
Sodium oxide $\left(\mathrm{Na}_{2} \mathrm{O}\right)$ & - & 0.75 \\
Manganese oxide $(\mathrm{MnO})$ & - & 0.35 \\
Titanium dioxide $\left(\mathrm{TiO}_{2}\right)$ & - & - \\
\hline
\end{tabular}


per required responses. In the second step, all the designed tests were performed in the laboratory by following obtained design in the former step. In the mathematical modeling step, different models were developed by analyzing the effect of different mix design ratios (SF and FM content) on various responses, i.e., mechanical properties of fat clays. Generally, the quadratic models were developed to compute the responses which were established as of first-, second-, or third-degree polynomials; the general form of the equation is as follows:

$\hat{Y}(x)=\alpha_{0}+\sum \alpha_{i} x_{i}+\sum \alpha_{i i} x_{i}^{2}+\sum \alpha_{i j} x_{i} x_{j}$

where $\hat{Y}$ is the predicted response and $\alpha$ and $x_{i, j}$ represent coefficients and $i$ th and $j$ th random variables of a full quadratic model. The coefficients were calculated using numerical regression based on the potential impact of independent variables on the response and their probabilistic distribution. The health of the developed model was checked based on various statistical indicators, i.e., coefficient of determination $\left(R^{2}\right)$, adjusted $R^{2}\left(\operatorname{Adj} R^{2}\right)$, predicted $R^{2}\left(\right.$ Pred $\left.R^{2}\right)$ adequate precision values, and analysis of variance (ANOVA) analysis describe as follows:

$R^{2}=\frac{S S R}{S S R+S S M}$

$\operatorname{Adj} R^{2}=1-\frac{n-1}{n-p}\left(1-R^{2}\right)$

$\operatorname{Pred} R^{2}=1-\frac{\text { PRESS }}{S S T}$

$A P=\frac{\max (\hat{Y})-\min (\hat{Y})}{\sqrt{\frac{p \sigma^{2}}{n}}}$

where $S S R$ and $S S M$ are residual and mean sum of squares, respectively; $p$ and $n$ are model parameters containing intercept and the number of observations, respectively; SST and PRESS are the total sum of square and the prediction error sum of squares, respectively; and $\sigma^{2}$ is the mean square of residual estimated by ANOVA analysis. In addition, prediction accuracy is also measured by comparing the predicted and actual values of the database (ur Rehman and Zhang 2021). Similarly, the normality control and equal variance assumption were conducted by comparing the residue to the predicted response variables. Afterward, optimized mix design was determined by engaging mathematical models established in step iii in an algorithm to determine the desirability function. Finally, the responses of optimized mix design determined in step iv were validated against actual test results.

\section{Design of experiment}

The face-centered central composite design (FCCCD) approach was employed in the current study, to design the experimental scheme. Initially, the boundary conditions were defined for the experimental scheme with two variables having different maximum and similar minimum values (Table 3). Fourteen experiments were designed with 6 central points and 8 axial points using FCCCD constraints. In the center points, the curvature of the built-in function of responses with independent variables was defined. The addition of axial points allowed the effective estimation of pure quadratic terms of available curvature (Güllü and Fedakar, 2017). Two additional axial points were also incorporated to enhance the database making the total sets of experiments to be 16. In addition, four responses were selected for the evaluation, i.e., $q_{u}$ and $C B R$ value, brittleness index $\left(I_{B}\right)$, and deformability index $\left(I_{D}\right)$, wherein $q_{u}$ and $C B R$ values were used to evaluate strength properties of the soil and $I_{B}$ and $I_{D}$ were used to evaluate the ductility of the soil (Table 4).

Sample preparation and testing Considering the designed experimental scheme, different tests were conducted including unconfined compression tests and $C B R$ tests. Standard compaction tests were also conducted to determine the optimum water content $\left(w_{\text {opt }}\right)$ and maximum dry density $\left(\gamma_{d}\right)$ of soil samples, since samples for the response measuring tests were prepared at the standard $w_{o p t}$ and $\gamma_{d}$ (Shehzad et al. 2015; Khalid and Rehman 2018). Shredded FM and SF were diligently mixed using a soil mixer to circumvent the fiber breakage and segregation in the soil-additive matrix. A strain-controlled axial load was applied to the sample at a rate of $1.0 \pm 0.1 \mathrm{~mm} / \mathrm{min}$ during the unconfined compression test according to ASTM D2166. The axial strain was

Table 3 Boundary condition of factors in RSM

\begin{tabular}{|c|c|c|c|c|c|c|c|c|c|}
\hline \multicolumn{4}{|c|}{ Variables } & \multicolumn{6}{|l|}{ Levels } \\
\hline Name & Code & Units & Subtype & Minimum & Maximum & Coded values & & Mean & Std. dev \\
\hline SF & $A$ & $\%$ & Continuous & 0 & 16 & $-1.00=0.00$ & $1.00=16.00$ & $0.00=8.5$ & 5.26 \\
\hline FM & $B$ & $\%$ & Continuous & 0 & 1.2 & $-1.00=0.00$ & $1.00=1.20$ & $0.00=0.6375$ & 0.38 \\
\hline
\end{tabular}


Table 4 Face-centered central composite design experiments and test results

\begin{tabular}{llllllr}
\hline Run & SF $(\%)$ & FM $(\%)$ & $q_{u}(\mathrm{kPa})$ & $I_{B}$ & $I_{D}$ & $C B R(\%)$ \\
\hline 1 & 0 & 0.6 & 280.1 & 0.05 & 0.96 & 5.6 \\
2 & 8 & 0.6 & 2121 & 0.71 & 0.91 & 43.1 \\
3 & 8 & 0.6 & 2121 & 0.71 & 0.91 & 43.1 \\
4 & 16 & 0.6 & 2993 & 1.24 & 0.72 & 61.3 \\
5 & 8 & 0.6 & 2121 & 0.71 & 0.91 & 43.1 \\
6 & 16 & 1.2 & 3378 & 1.20 & 0.77 & 70.2 \\
7 & 8 & 0.6 & 2121 & 0.71 & 0.91 & 43.1 \\
8 & 8 & 0.0 & 1730 & 1.04 & 0.65 & 36.0 \\
9 & 0 & 0.0 & 153.4 & 0.00 & 1.00 & 3.1 \\
10 & 8 & 0.6 & 2121 & 0.71 & 0.91 & 43.1 \\
11 & 8 & 0.6 & 2121 & 0.71 & 0.91 & 43.1 \\
12 & 8 & 1.2 & 2389 & 0.46 & 0.99 & 49.4 \\
13 & 0 & 1.2 & 325.1 & 0.09 & 0.98 & 6.5 \\
14 & 16 & 0.0 & 2800 & 1.52 & 0.54 & 64.0 \\
${ }^{\mathrm{a}} 15$ & 8 & 0.9 & 2500 & 0.56 & 0.98 & 52.0 \\
${ }^{\mathrm{a}} 16$ & 16 & 0.9 & 3077 & 1.19 & 0.74 & 64.0 \\
\hline
\end{tabular}

${ }^{\text {a Additional tests }}$

applied in a manner that both $q_{u}$ and residual strength $\left(q_{r}\right)$ (if exist) could be measured (Rehman and Zhang, 2019, Rehman et al., 2020, Rehman and Zhang, 2021). The $I_{B}$ and $I_{D}$ were computed by determining $q_{u}, q_{r}$, and strain at failure $\left(\varepsilon_{f}\right)$ for treated and untreated soils using the following equations:

$I_{B}=\frac{q_{u}}{q_{r}}-1$

$I_{D}=\frac{\varepsilon_{f(\text { treated })}}{\varepsilon_{f(\text { untreated })}}$

In addition, un-soaked $C B R$ tests were carried out by following ASTM D1883-14, to examine the strength characteristics of the soil for use in subgrade construction. It is important to mention that 14-day curing is selected in the current study as by a trial study it was observed that ABAtreated soil gained substantial $q_{u}$ after 14 days of curing and the marginal increase occurred beyond this curing time (ur Rehman and Khalid 2021). Thus, to avoid large delays and complexity, 14-day curing of sample for the main study was adopted, and it was done by wrapping samples in a polythene cling sheet and placing them in a desiccation jar.

\section{Results and discussions}

\section{Mathematical modeling}

ABA mix design effect on $q_{u}$ The effect of different mix designs of SF and FM on the $q_{u}$ was evaluated, and three- dimensional (3D) surface response and contour plots are plotted for the best-fit mathematical model in Fig. 1. It was observed that $q_{u}$ increased with the increase in the SF and FM in the mix design; a large increase was observed for the increase in the former as compared to latter. Moreover, with an increase in the FM content in the ABA, the $q_{u}$ of treated soil increased to a certain limit and showed a slight decrease (Fig. 1a). A complete quadratic model, without transformation, was evaluated and then modified with back-calculation analysis to keep $p<0.05$ for all intercepts. The following mathematical model is derived to define $q_{u}$ using the input variables, i.e., $\mathrm{SF}$ and $\mathrm{FM}$, by keeping $\lambda$ value equals to unity:

$q_{u}=2122.06+1380.3 A+538.52 B+85.25 A$.

$B-488.74 A^{2}-0.33 B^{2}-191.15 A^{2} \cdot B-176.32 B^{3}$

where $A$ and $B$ are SF and FM, respectively. Figure $1 \mathrm{~b}$ shows the contour plot of this response surface. A good agreement between the actual and predicted values of $q_{u}$ was observed around $45^{\circ}$ line (Fig. 1c), showing the significance of Eq. 8. The normal probability plot of the RSM model for $q_{u}$ is constructed in Fig. 1d. It can be seen (Fig. 1d) that for this model, against normal probability, the internally studentized residuals were tracked around a straight line, which means that the normal assumption was met. In addition, the perturbation plot is presented in Fig. 1e, for a better understanding of the effect of SF and FM contents on the $q_{u}$ of ABA-treated soils at a particular point. A steep slope was observed with an increasing trend for both SF and FM, which means that the $q_{u}$ increased with an increase in SF and FM; however, a more steep line and a larger increase in the $q_{u}$ was observed with an 


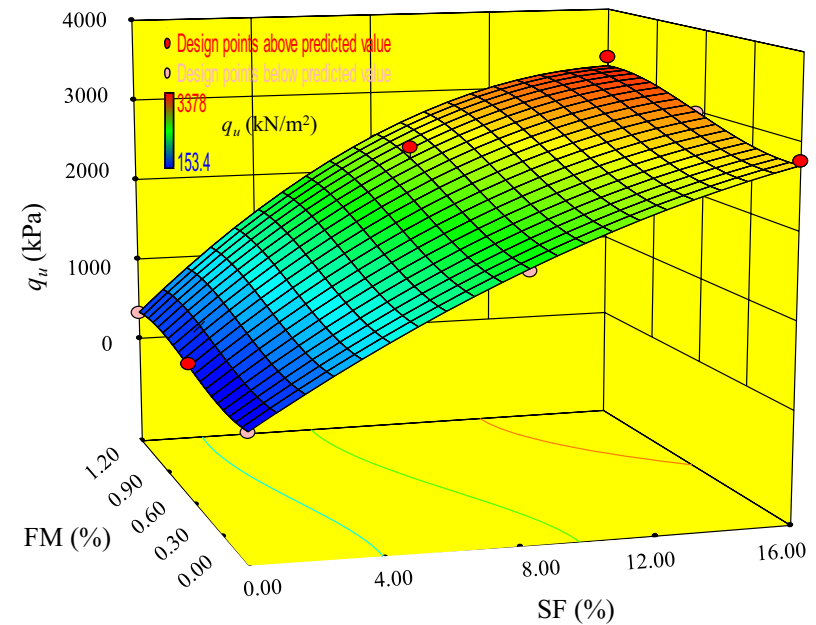

(a)

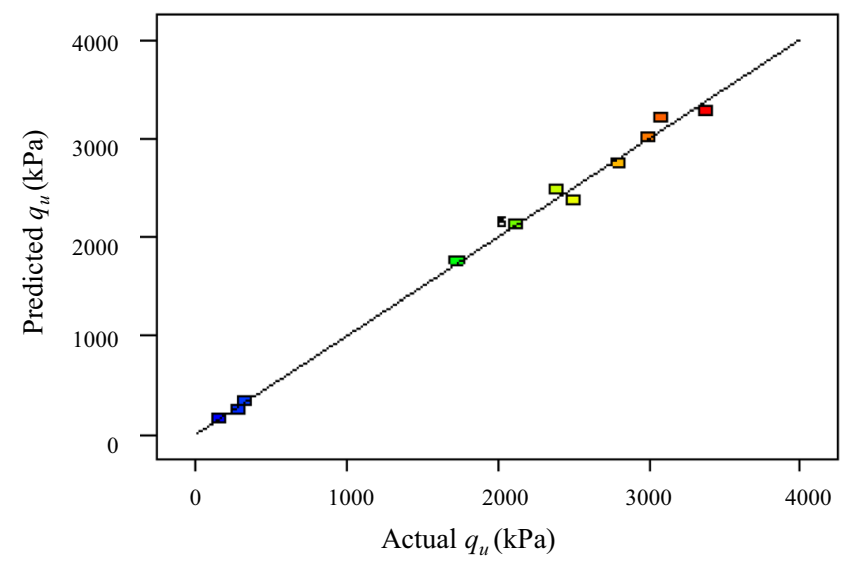

(c)

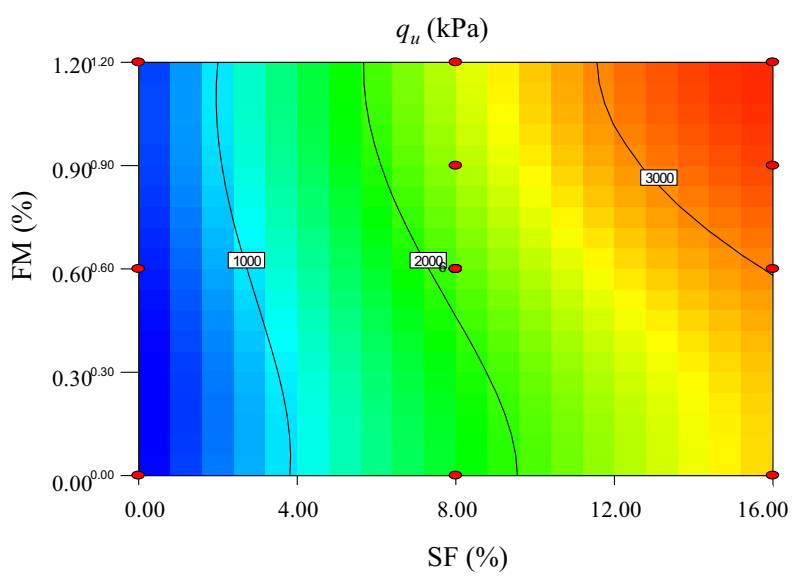

(b)

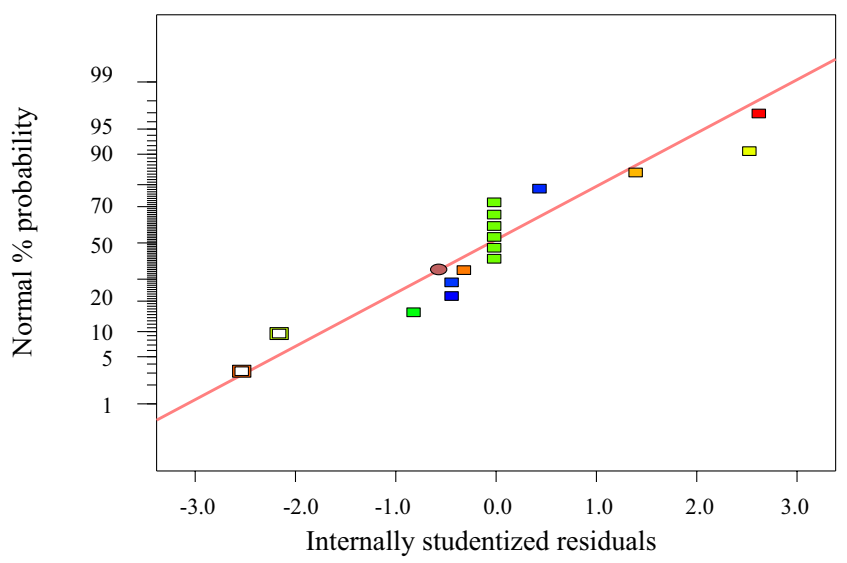

(d)

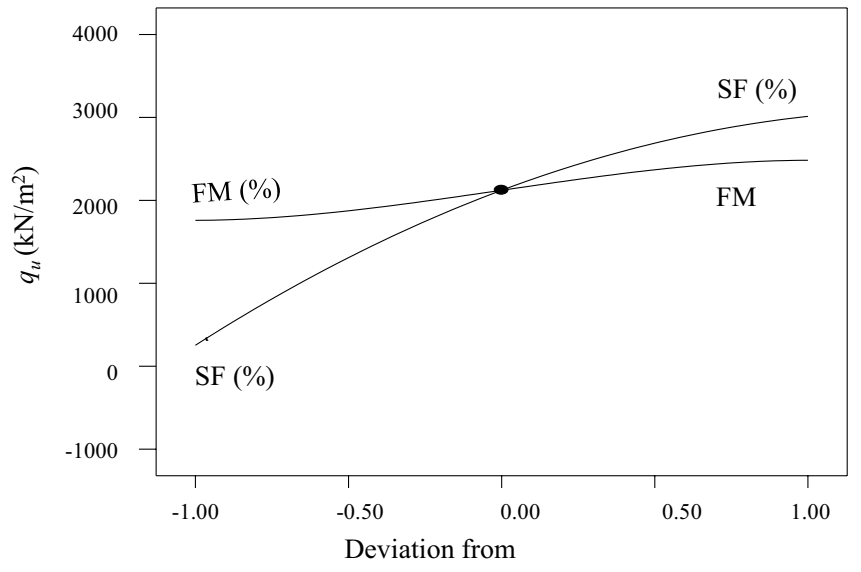

(e)

Fig. 1 RSM-based analysis of $q_{u}$ : a 3D response surface, $\mathbf{b}$ contour plot, $\mathbf{c}$ predicted versus actual value, $\mathbf{d}$ normal probability plot, and e perturbation plot 
increase in the SF, which means that SF is a more sensitive parameter for the $q_{u}$ of ABA-treated soil. These analyses depict the importance of the presence of SF in the FM-based ABA in ameliorating the strength of a fat clay.

$A B A$ mix design effect on $I_{B}$ Figure 2 presents the effect of SF and FM contents in an ABA on the $I_{B}$ of the treated soil, which is an inverse representation of the ductility of the soil. It was observed that $I_{B}$ increased as the SF content was increased; conversely, $I_{B}$ decreased as the FM was increased in the ABA. However, when FM was added in the absence of SF, the $I_{B}$ almost remained unchanged. A $3 \mathrm{D}$ response surface was observed to capture the effect of mix design on $I_{B}$, which can be quantified by the following mathematical model (Fig. 2a); the contour plot of this surface is shown in Fig. $2 b$.

$I_{B}=0.7+0.63 A-0.14 B-0.1 A \cdot B$

A good agreement along the $45^{\circ}$ line was observed between actual and predicted $I_{B}$ values using Eq. 8 (Fig. 2c). In addition, in the normal distribution plot (Fig. 2d), the data points coincided with the normal line showing that data was normally distributed. Moreover, the perturbation plots showed that the increase in the SF and FM improved and deteriorated the $I_{B}$ value, respectively, in a sensitive manner (Fig. 2e). However, deterioration caused by SF was observed to be slightly larger than the improvement imparted by the FM. This shows that the deterioration caused by the SF can be well ameliorated by the FM. This is in line with past literature on fiber and cementitious improvement of soil (Tiwari et al. 2020; Elkhebu et al., 2019; Abdi et al. 2021). This shows that FM can do damage control in terms of deterioration of ductility imparted by the SF while generating cementation in ABA-treated soil. FM acts as a reinforcing agent in the cemented soil matrix, which is responsible for high strength, to ensure that the ductility of treated soil does not vanish. This proves that assimilated SF and FM can ensure balanced mechanical characteristics of treated soil as postulated. On the other hand, the aforementioned analysis also shows that for maximum balanced amelioration of strength and ductility, optimum mix design should be adopted.

ABA mix design effect on $I_{D}$ The effect of the mix design of ABA was also assessed on $I_{D}$, as shown in Fig. 3. The trend of the effect of SF and FM content on the $I_{D}$ was observed to be almost similar to that on $I_{B}$. The following quadratic model with no transformation $(\lambda=1)$ was obtained to define the 3D surface response of the $I_{D}$ using SF and FM as the predictors (Fig. 3a).

$I_{D}=0.91-0.16 A+0.093 B+0.059 A \cdot B-0.047 A^{2}-0.052 B^{2}$

The contour plot of this 3D surface response is shown in Fig. 3b. For this model, a reasonably less scatteredness of the actual and predicted value of $I_{D}$ was observed along the $45^{\circ}$ line (Fig. 3c). The data was normally distributed as verified by the distribution of internally studentized residuals along a straight line against normal probability (Fig. 3d). The perturbation plot shows that SF and FM were almost equally sensitive parameters in terms of $I_{D}$, wherein the former posed a negative impact and latter posed a positive impact on $I_{D}$ (Fig. 3e). Thus, deterioration of deformability caused by SF can be controlled by FM content in the ABA, proving the importance of integrating SF and FM to prepare a balanced cementing admixture for fat clay.

ABA mix design effect on CBR-value $C B R$-value was observed to increase with the addition of both $\mathrm{SF}$ and FM; however, generally, a slight downward curvature was observed as the FM content increased to its maximum value set in this study (Fig. 4). Consequently, a 3D response surface was observed to capture the effect of SF and FM on the $C B R$-value of treated soil bounded with the following mathematical model (Fig. 4a).

$$
\begin{aligned}
C B R & =42.18+26.33 A+12.27 B+0.007 A \cdot B-8.78 A^{2} \\
& +0.75 B^{2}-5.42 A^{2} \cdot B+3.76 A \cdot B^{2}-5.14 B^{3}
\end{aligned}
$$

The contour plot of this response surface is presented in Fig. 4b. A marginal deviation among actual and predicted values was observed for this model with a normal data distribution (Fig. 4c-d), showing the statistical reliability of this model. The perturbation plot shows that both SF and FM contributed to the $C B R$-value; however, $\mathrm{SF}$ is a more sensitive variable (Fig. 4e). It is important to note that $C B R$ value is an important indicator to determine the suitability of soil for subgrade construction of roads and highways. These results show that the potential of a native fat clay to be used in the subgrade construction can be enhanced by stabilizing it using the appropriate mix of ABA.

\section{Statistical analysis of ABA mix design models}

For further evaluation of developed models in the current study, various important statistical model validation parameters are presented in Table 5. A high value of $R^{2}, \operatorname{Adj} R^{2}$, and Pred $R^{2}$ for all the developed models in the current study indicates the good health of these models. The difference between all these parameters was observed to be less than 0.2 which indicates that these parameters are rationally in the agreement. A high value of adequate precision factor (adequate precision $>4$ ) was observed for all the developed models; this indicates that these models can reliably be used to predict the corresponding responses. The ANOVA results for a full regression model are also presented in Table 5, a high $F$ value $(F>3.9)$ was observed for all models, and very 


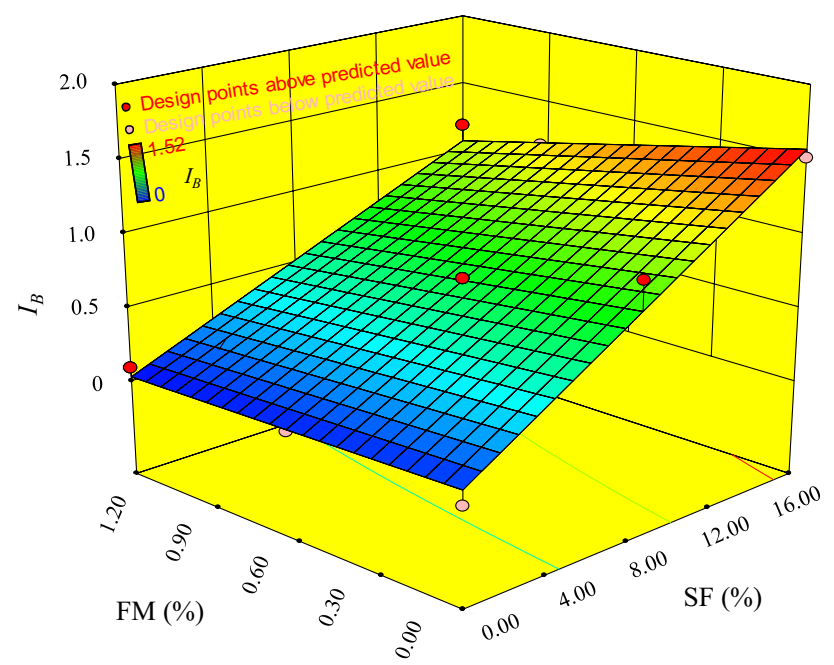

(a)

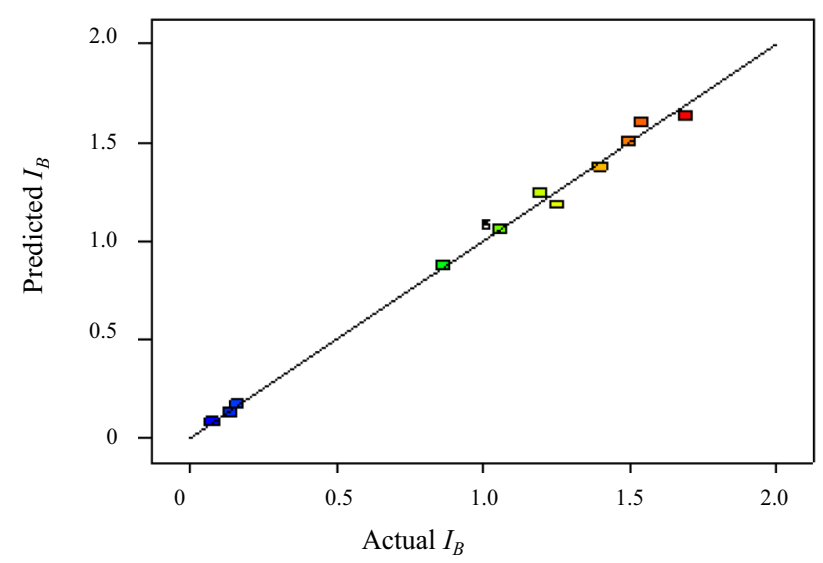

(c)

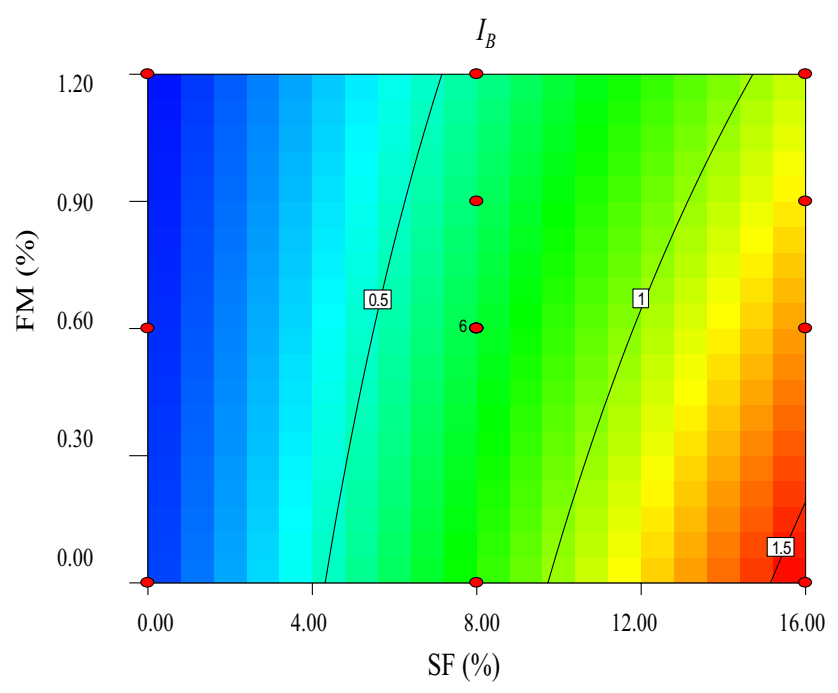

(b)

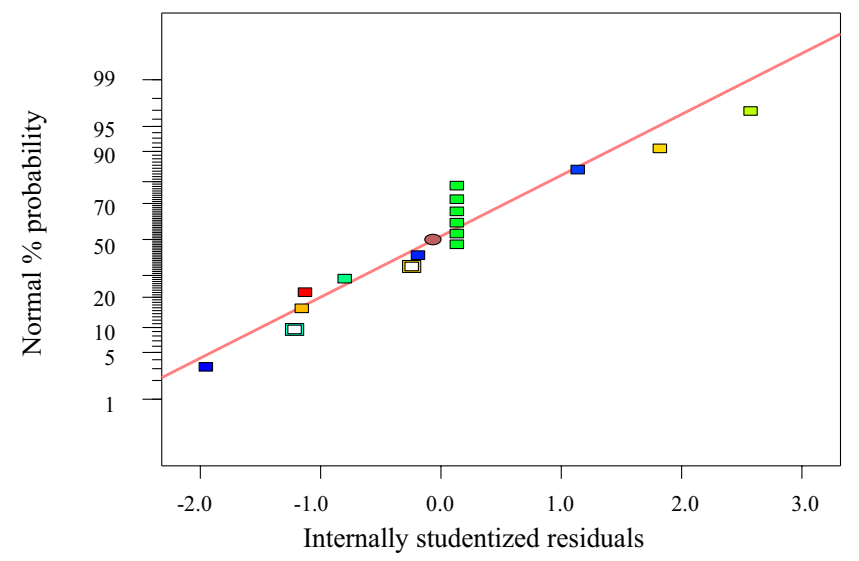

(d)

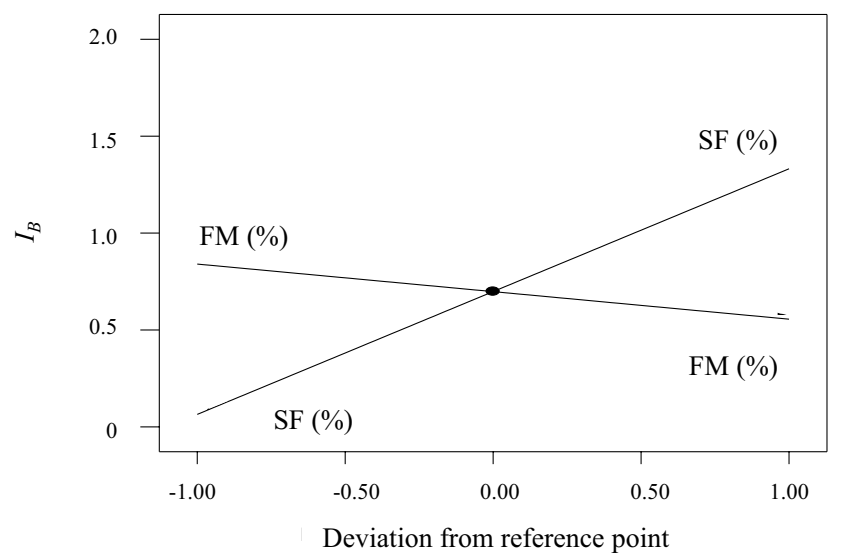

(e)

Fig. 2 RSM-based analysis of $I_{B}$ : a 3D response surface, $\mathbf{b}$ contour plot, $\mathbf{c}$ predicted versus actual value, $\mathbf{d}$ normal probability plot, and e perturbation plot 


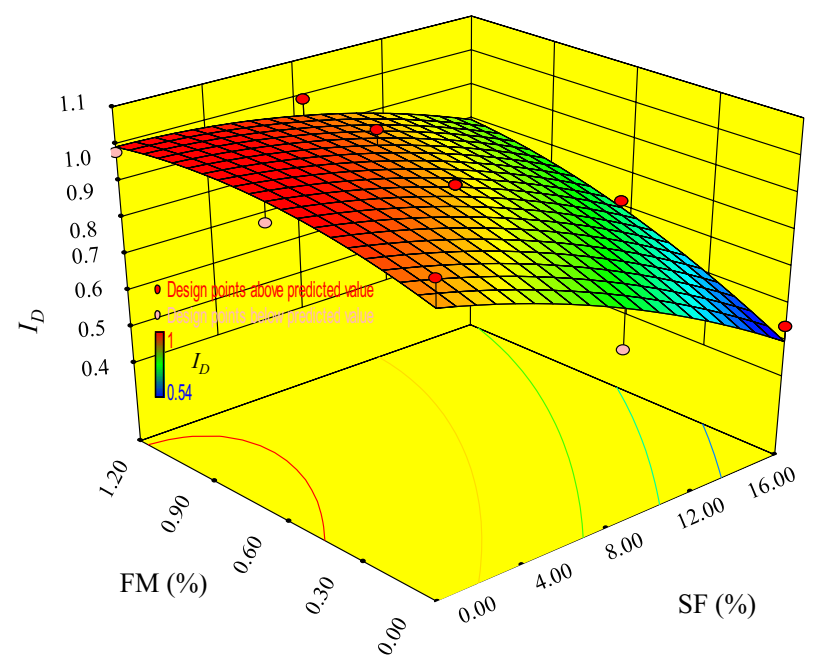

(a)

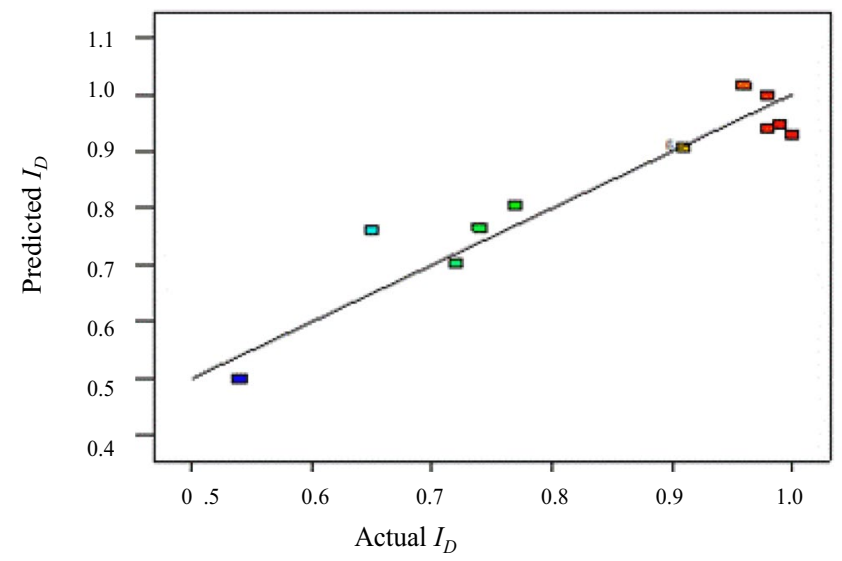

(c)

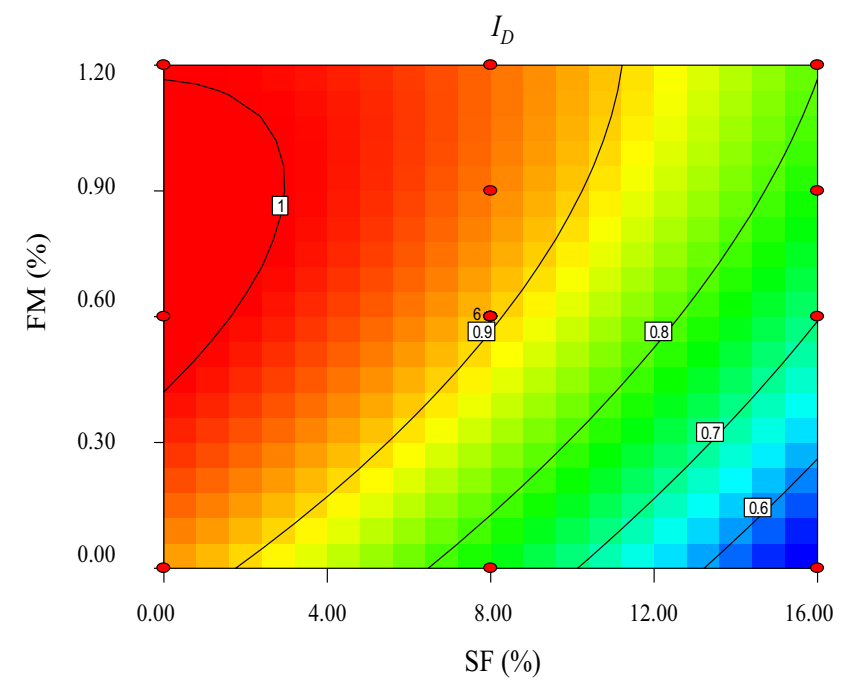

(b)

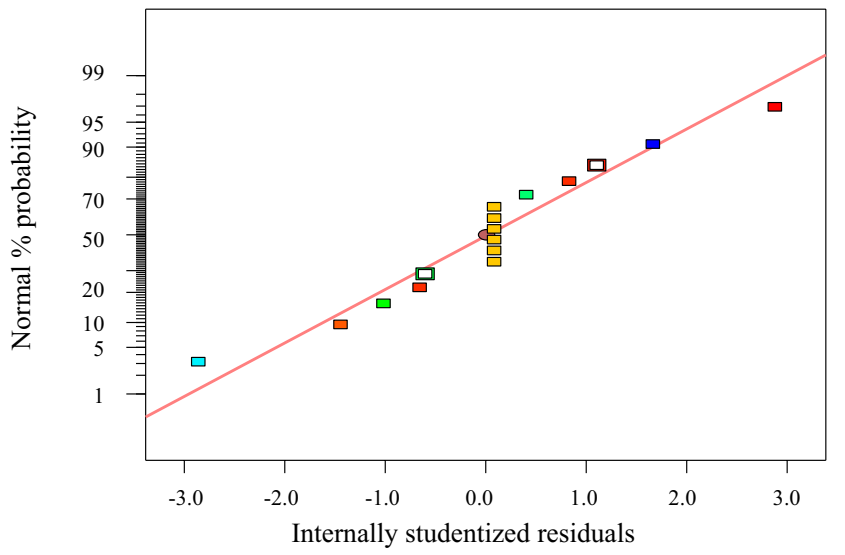

(d)

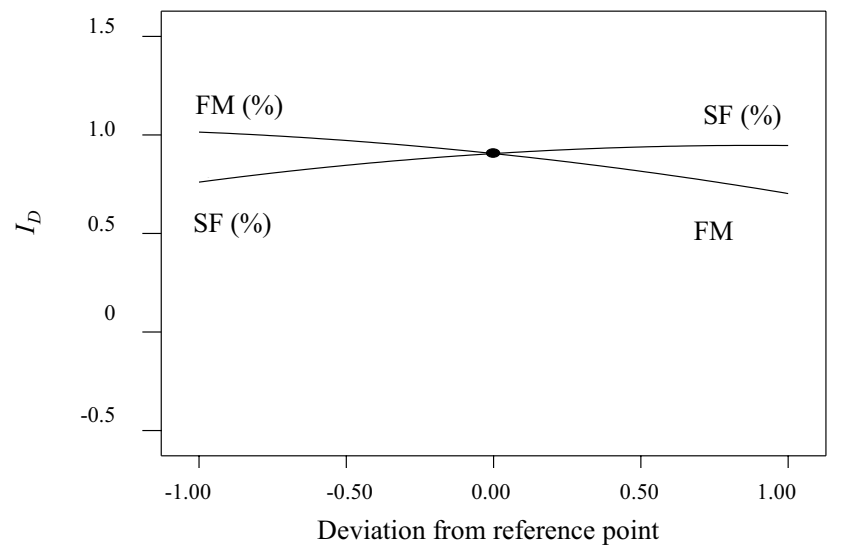

(e)

Fig. 3 RSM-based analysis of $I_{D}$ : a 3D response surface, $\mathbf{b}$ contour plot, $\mathbf{c}$ predicted versus actual value, $\mathbf{d}$ normal probability plot, and e perturbation plot 


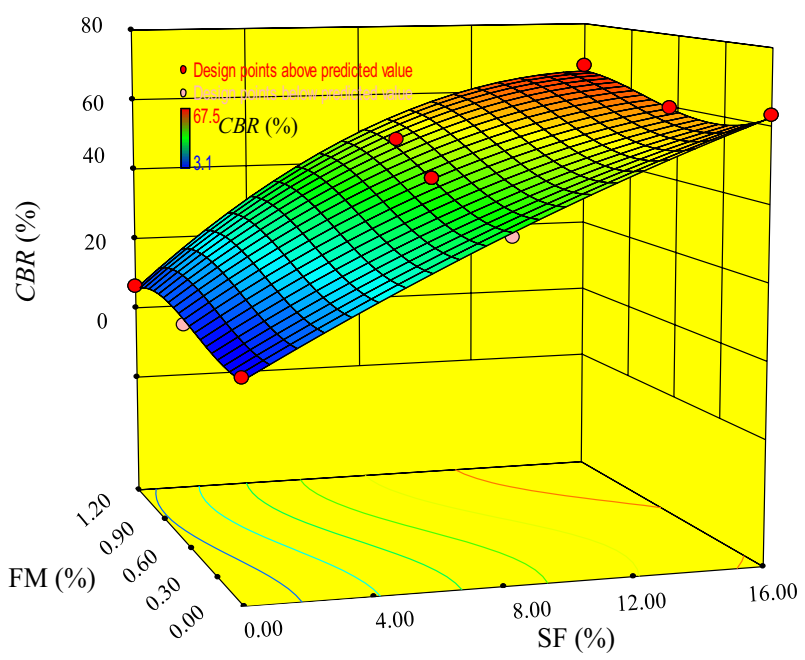

(a)

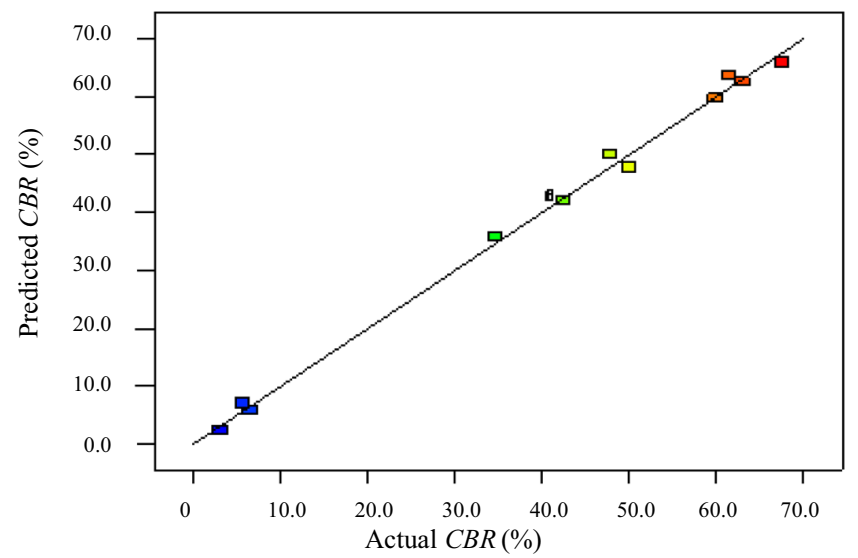

(c)

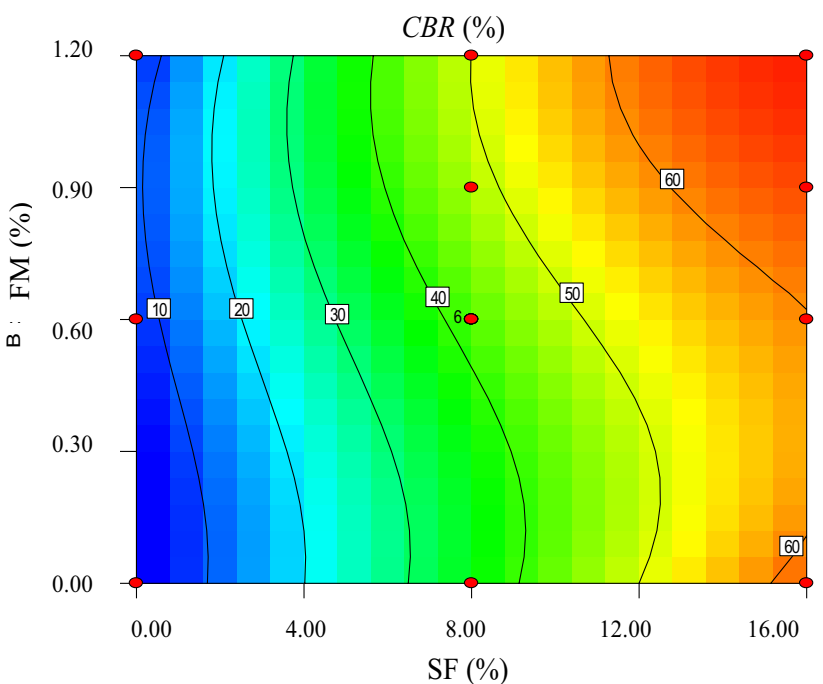

(b)

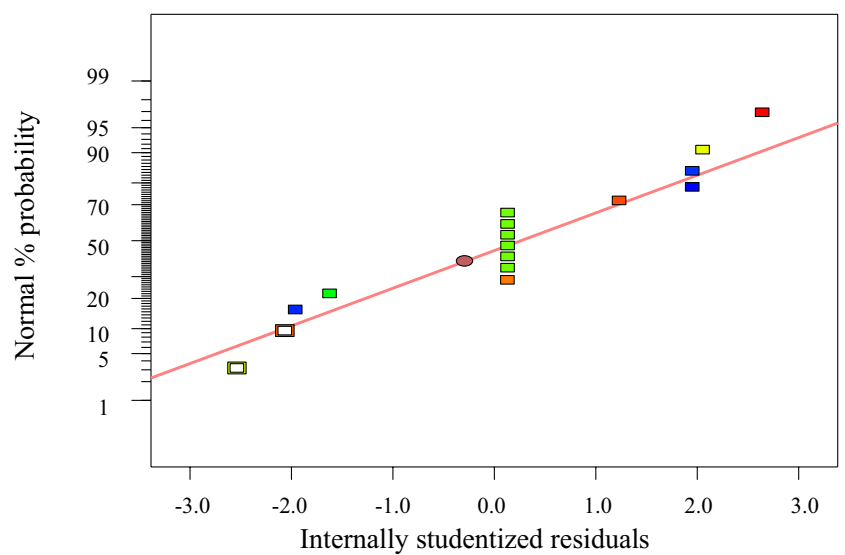

(d)

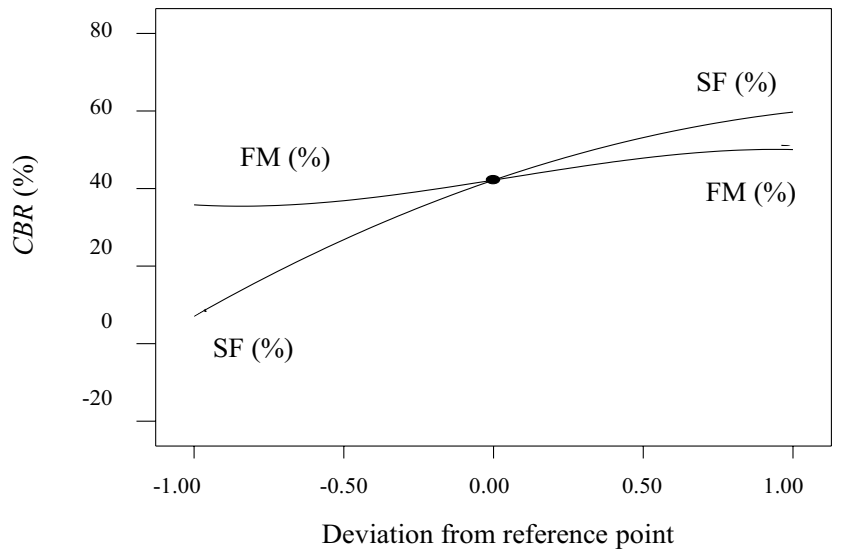

(e)

Fig. 4 RSM-based analysis of $C B R$ : a 3D response surface, $\mathbf{b}$ contour plot, $\mathbf{c}$ predicted versus actual value, $\mathbf{d}$ normal probability plot, and e perturbation plot 


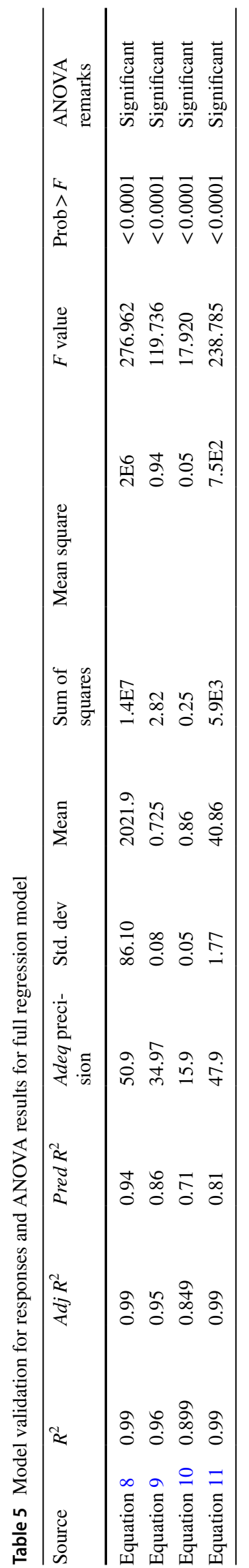

insignificant values of probability $(p<0.05)$ were observed. These results show that all the models developed in the current study are having good statistical health.

Optimization of ABA mix design In order to establish the optimum quantities for the independent variables (SF and $\mathrm{FM}$ ) in the $\mathrm{ABA}$ for maximum performance considering strength behavior in terms of $q_{u}$ and $C B R$-value and ductility behavior in terms of $I_{B}$ and $I_{D}$, an optimization study was carried out in this paper using the approach to compute the individual desirability functions $(d i)$ outlined for each subjected dependent (response) variable as follows:

$d_{i}\left(\hat{Y}_{i}\right)= \begin{cases}0 & \\ \left(\frac{\hat{Y}_{i}(x)-\operatorname{Max}_{i}}{\operatorname{Max}_{i}-T_{i}}\right)^{s} & \text { if } \hat{Y}_{i} \geq \widehat{Y}_{i}(x) \geq \operatorname{Max}_{i} \\ \left(\frac{\hat{Y}_{i}(x)-\operatorname{Min}_{i}}{\operatorname{Max}_{i}-T_{i}}\right)^{t} & \text { if } \operatorname{Min}_{i} \geq \widehat{Y}_{i}(x) \geq T_{i} \\ 0 & \text { if } \hat{Y}_{i}(x)>\operatorname{Min}_{i}\end{cases}$

where $\operatorname{Min}_{i}$ and $\operatorname{Max}_{i}$ are the minimization and maximization values, respectively, and $T_{i}$ is the target value, and $s$ and $t$ render the strictness level of the $d_{i}$ function for maximization and minimization goals. Global desirability $(D)$ based on $d i$ is computed using the following equation (Ferdosian and Camões 2017; Pinheiro et al. 2020):

$D=\left(d_{1}{ }^{r_{1}} \cdot d_{2}^{r_{2}} \cdot d_{3}^{r_{3}} \cdots d_{n}^{r_{n}}\right)^{\frac{1}{\Sigma r_{i}}}=\left(\int_{i-1}^{n} d_{i}^{r_{i}}\right)^{\frac{1}{\Sigma r_{i}}}$

where $n$ is the number of responses and $r_{i}$ is the sensitivity factor for each response, which is increasingly rated from 1 to 5 . The overall desirability was taken as the arithmetic mean of all individual desirability for which 0 and 1 indicate the least and highest threshold values. It is important to mention that in this study, to outline the strength behavior of treated soil, $q_{u}$ and $C B R$-value were selected so that optimized solution could be accepted for a wide range of applications, i.e., buildings, roads and highways. In this study, a maximization goal was adopted for $q_{u}, C B R$-value, and $I_{D}$, and a minimization goal was selected for the $I_{B}$ (Fig. 5a). Moreover, the maximum $C B R$-value was limited at $50 \%$ as this indicates a momentous value. For all these goals, a significant $D$-value close to 1 was obtained for a mix design having $7.9 \%$ SF and 1.2\% FM (Fig. 5b). This indicates that with this mix design, the best possible balanced amelioration of the mechanical properties considering strength and ductility could be achieved. It can be observed that increasing SF beyond the achieved optimized mix design value decreases desirability. Moreover, this mix design may change as goals are changed; for instance, by ignoring $C B R$-value in optimization and keeping goals for remaining responses to be the 
Fig. 5 Optimization of mix design: a goal setting and $\mathbf{b}$ desirability analysis

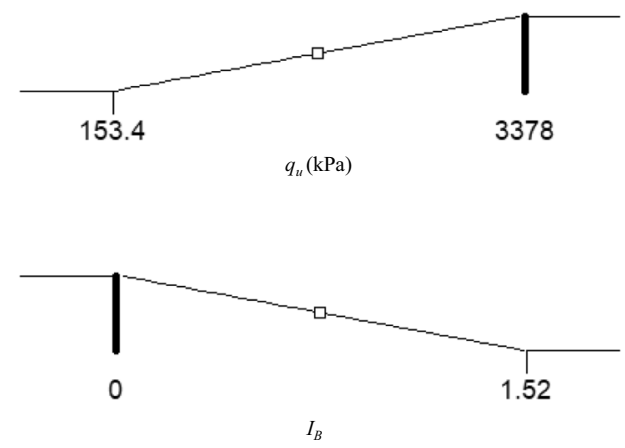

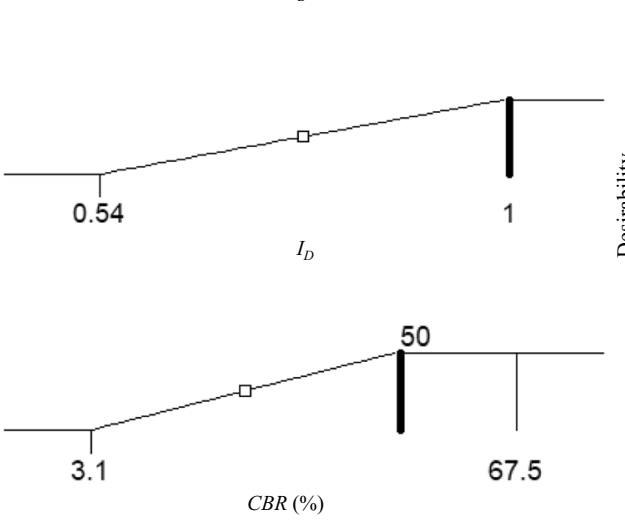

(a)

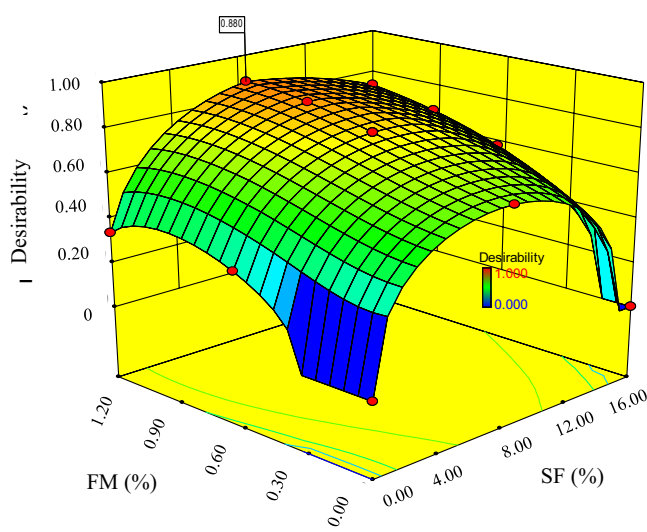

(b) same, the optimized mix design was obtained at $6.2 \%$ of SF and $1.2 \% \mathrm{FM}$ with almost similar $D$-value. These analyses show that change in the mix design of ABA has a significant impact on the mechanical performance of the ABA-treated soil. Thus, to achieve balanced mechanical amelioration of fat clay, optimized mix design of ABA should be used in the field.

\section{Validation of ABA mix design}

The final step in RSM is the validation of the developed models. For this purpose, an experimental program was conducted for the optimized mix design obtained in the current study. Thus, by mixing $7.9 \%$ and $1.2 \%$, an ABA was prepared and mixed with soil to prepare a sample for the unconfined compression and $C B R$ tests. Table 6 presents the comparison of predicted responses and actual test results for the optimized mix design; it was observed that the developed models can reasonably predict different responses with a fringe error (maximum error $\leq 8 \%$ ). The stress-strain curve obtained from the unconfined compression test is also presented in Fig. 6a, and it can be observed that high strength and reasonable ductility were achieved with the optimized mix design of the current study. In addition, the ductility was observed to be mainly catered by the fiber bridging effect imparted by FM fibers in the tension cracks as can be seen in open tension cracks of the ABA-treated sample after failure (Fig. 6b).

\section{Cleaning aspects}

Cleaner production and pollution reduction measures by productive waste reuse can benefit both the economy and the environment. In this study, two waste by-products are mixed to prepare an ABA as a replacement of conventional fat clay stabilizers, i.e., cement. In addition, the appropriate mix design of ABA as determined in the current study presents balanced amelioration of the fat clays in terms of strength and ductility characteristics, unlike the conventional stabilizing materials which only ameliorate strength
Table 6 Response results of the experiment and prediction model for optimal mix design

\begin{tabular}{llllllll}
\hline Response & $\mathrm{SF}(\%)$ & $\mathrm{FM}(\%)$ & $q_{u}(\mathrm{kPa})$ & $I_{B}$ & $I_{D}$ & $C B R(\%)$ & Desirability \\
\hline Predicted & 7.9 & 1.2 & 2481.2 & 0.50 & 0.95 & 50.0 & 0.88 \\
Experimental & 7.9 & 1.2 & 2380.0 & 0.45 & 0.97 & 49.0 & \\
Error (\%) & - & - & 3.7 & 8.0 & 4.5 & 2.0 & \\
\hline
\end{tabular}


Fig. 6 Validation of optimized mix design: a unconfined compression test result and $\mathbf{b}$ fiber bridging

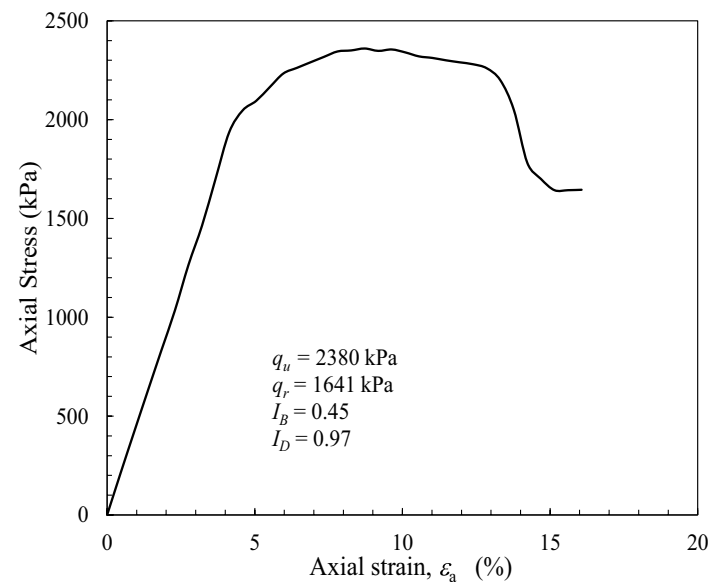

(a)

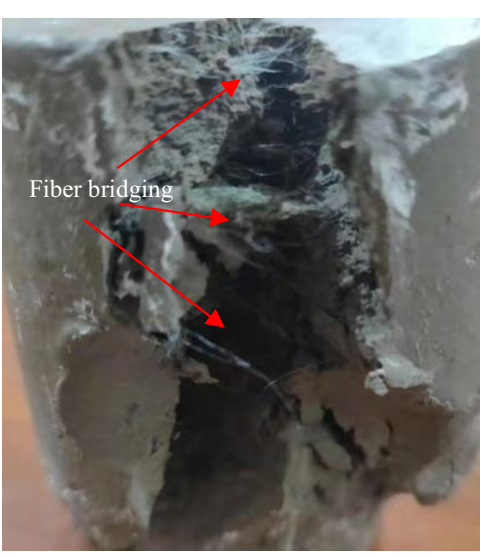

(b) characteristics of the soil. Thus, ABA could help in mitigation of environmental and natural resource consumption issues caused by the production of conventional stabilizing material and cleaning of different emerging wastes, i.e., FM waste and SF through more efficient soil stabilization than conventional materials.

As per the modified Nzediegwu and Chang (2020) model, the FM waste is estimated to be around $11,308 \mathrm{Mg} /$ day in Asia alone which is an emerging problem threatening to pose severe long- and short-term environmental issues, e.g., disposal and burning of non-renewable and non-biodegradable FM waste material release microplastics and $\mathrm{CO}_{2}$ to the ecosystem, respectively (Sangkham 2020). The actual production of SF is still unknown, and this production is ever increasing due to industrialization; however, roughly the estimated production of SF waste is around $5480 \mathrm{Mg} /$ day globally (Türköz et al. 2018). Environmentalists are concerned about the correct disposal of $\mathrm{SF}$ as an industrial waste since it can create serious health problems if it is directly released into the ecosystem. To estimate the magnitude of waste by-products that could be incorporated in a geotechnical application through the current soil stabilization scheme, the mass of stabilizing material, $M_{s t}$, required for the soil stabilization in any project is computed using the following equation:

$M_{s t}=\frac{\gamma_{s} v_{s} \Delta_{s t}}{100}$

where $\gamma_{s}$ and $v_{s}$ are the specified dry density and volume of the soil and $\Delta_{s t}$ is the percentage by weight of stabilizing material. For instance, using an optimized ABA mix design for a $1 \mathrm{~km}$ two-lane road, to stabilize $0.25 \mathrm{~m}$ thick and $18.5 \mathrm{kN} / \mathrm{m}^{3}$ of subgrade soil, $43 \mathrm{Mg}$ and $281 \mathrm{Mg}$ of FM and SF waste could be utilized, respectively. Thus, the proposed optimized ABA has a vast potential of productively managing FM and SF wastes. In addition, the required amount of cement (for $\Delta_{s t}=10 \%$ ) to stabilize soil with similar specifications as mentioned above could be around $356 \mathrm{Mg}$. Thus, using the proposed optimized ABA for a $1 \mathrm{~km}$ two-lane road project in place of cement as a fat clay stabilizer could avoid carbon dioxide emission of around $79,032 \mathrm{~kg}$ of $\mathrm{C}$ and can also save $42,720 \mathrm{kWh}$ and $1174.8 \mathrm{GJ}$ of electrical and thermal energy, respectively, by restricting cement manufacturing (Sousa and Bogas, 2021). The determined ABA in this study has the potential to promote the pragmatic reuse of the FM waste in soil stabilization. This can help to resolve the FM waste disposal and pertinent environmental problems, mechanical vulnerabilities of fat clays, and natural construction material consumption-related issues. Thus, the utilization of optimized ABA holds promising environmental and economic benefits.

Cleaner production encompasses many operational practicalities of safe health/environmental practice including safe logistics of waste collection and making it ready for the final application. Reutilization of SF in the construction industry is well known, and safe protocols to collect it from the parent industry and making it ready for application in the construction industry are well in practice. In contrast, the use of FM waste in construction is not well established, and due to large health risks involved with this waste, astute protocols of FM waste handling and disinfection are needed to be established and followed. FM waste is needed to be handled as hazardous waste, and thus, care must be taken from collecting it from the primary consumer level to the proposed geotechnical application. The proposed cleaner production process of FM waste involves the collection, transportation, disinfection shredding, and final geotechnical application as shown in Fig. 7. Carefulness must be maintained in all the involved steps (Fig. 7). For instance, during transportation, tarps or other dust-proofing materials should be used to cover delivery trucks, and less human interference should be involved in the handling of FM waste (Saberian et al. 


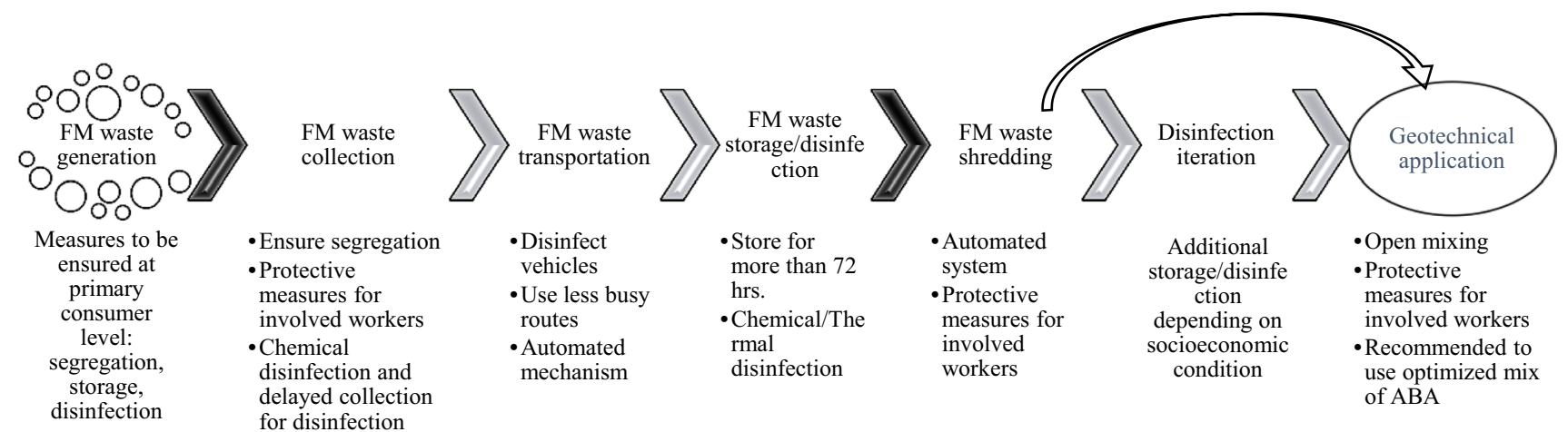

Fig. 7 Proposed procedure of FM waste management for fat clay stabilization (arrows in black indicate that delay is desirable for preceding activity)

2021). To restrict COVID-19 exposure at these stages, it is suggested to perform proper disinfection involving less human interference, by prolonged storage (not shorter $72 \mathrm{~h}$ ), chemical disinfectant, exposure of FM waste to sun and air (for more than $72 \mathrm{~h}$ ), or their combinations (Doan 2020; Haghani et al. 2020; Hamzavi et al. 2020; Lowe et al. 2020; Meyers et al. 2021; Suman et al. 2020). Moreover for the geotechnical application of FM waste, during shredding of FM and application to the soil, automated machinery should be involved as much as possible. Any worker involved in handling and application of FM waste in construction must be protected with PPE and regularly undergo health monitoring. The machinery, trucks, and logistics involved from collection to the geotechnical application of FM waste must be regularly disinfected.

\section{Conclusions}

In this study, a novel admixture prepared by blending SF and shredded FM is evaluated for the balanced treatment of mechanical properties of fat clay. For this purpose, RSM is applied and different mathematical models are developed to predict different responses, and the optimized mix designs are proposed considering the possible maximum performance of ABA to improve strength and cater brittleness of treated soil. The following are the findings of the current study:

- $\mathrm{SF}$ and FM contributed to the amelioration of strength characteristics, i.e., $q_{u}$ and $C B R$-value of the ABA-treated soil; however, the latter played a marginal role in comparison to the former. In addition, a slight curvature in the 3D response surface of strength characteristics of treated soil was observed beyond the central point towards increasing FM content showing that excessive use of FM in combination with SF may slightly deteriorate strength. On the other hand, SF content was observed to be a sensitive input of $\mathrm{ABA}$ in deteriorating the ductility of treated soil as indicated by the increase in $I_{B}$ and decrease in $I_{D}$. Conversely, FM content in ABA ameliorated the deteriorated ductility by SF. However, the deterioration impact of SF on ductility was slightly higher than the converse impact of FM. This shows that FM acts as a reinforcing agent in the cemented soil matrix, which is responsible for the attainment of high strength, to ensure that ABA-treated soil does not lose much ductility. However, 3D RSA emphasized that for maximum balanced amelioration of strength and ductility, optimum mix design should be determined.

- The mathematical models were developed in the current study to predict $q_{u}, I_{B}, I_{D}$, and $C B R$-value of ABA-treated soil for different mix designs of ABA. These models were observed to have high values of $R^{2}, A d j R^{2}$, and Pred $R^{2}$ with a difference among these parameters less than 0.2 . In addition, an insignificant $p$-value $<0.0001$ was observed for all models; thus, these models were statistically valid.

- For multiple applications, i.e., roads and buildings, the desired maximization of $q_{u}, C B R$-value, and $I_{D}$ and minimization of $I_{B}$ of treated soil were achieved by a singular mix design of ABA having 7.9\% SF and 1.2\% FM with a high $D$-value close to 1 . In addition, by ignoring $C B R$ value in optimization and keeping goals for remaining responses to be the same, the optimized mix design was obtained at $6.2 \%$ of SF and $1.2 \%$ FM with almost similar $D$-value. Thus, these application-based optimized ABA could be adopted in the field for maximum balanced amelioration of fat clay.

- The analysis of the cleaning aspect of this study showed that the use of optimized ABA in place of cement for subgrade improvement of $1 \mathrm{~km}$ two-lane road could avoid $\mathrm{CO}_{2}$ emission of around $79,032 \mathrm{~kg}$ of $\mathrm{C}$, save 42,720 $\mathrm{kWh}$ and $1174.8 \mathrm{GJ}$ of electrical and thermal energy, respectively, and clean $43 \mathrm{Mg}$ and $281 \mathrm{Mg}$ of FM and SF 
wastes, respectively. Thus, the current COVID-19-related and existing environmental problems could be minimized through this solution. However, proper protocols for disinfection and handling of the FM waste are required to be established and strictly followed before using it in soil stabilization.

It is important to mention here that the current study provided this geotechnical solution to reuse FM waste in fat clay stabilization by using unused FM due to COVID-19 restrictions; however, actual FM waste should be used after proper disinfection. The disinfection method of FM waste and its impact on soil stabilization potential were not included in the scope of the current study; carefully designed studies could be conducted for that purpose in the future.

Acknowledgements UET Taxila and NUST, Risalpur campus, are acknowledged for their support.

Author contribution ZR: Conceptualization, methodology, validation, investigation, writing original draft, formal analysis, and visualization. UK: Investigation, data curation, resources, validation, writing-review and editing, and visualization.

Data availability The datasets used and/or analyzed during the current study are available from the corresponding author on reasonable request.

\section{Declarations}

Ethics approval Not applicable.

Consent to participate Not applicable.

Consent for publication Not applicable.

Competing interests The authors declare no competing interests.

\section{References}

Abbey SJ, Eyo EU, Okeke CA, Ngambi S (2021) Experimental study on the use of RoadCem blended with by-product cementitious materials for stabilisation of clay soils. Constr Build Mater 280:122476

Abdi MR, Abbas G, Leila SC (2021) An investigation into the effects of lime on compressive and shear strength characteristics of fiberreinforced clays. J Rock Mech Geotech 13(4):885-898

AL-Soudany KY (2018) Improvement of expansive soil by using silica fume. Kufa J Eng 9(1):222-239

Boroujeni M, Saberian M, Li J (2021) Environmental impacts of COVID-19 on Victoria, Australia, witnessed two waves of Coronavirus. Environ Sci Pollut Res 28(11):14182-14191

Cheng VCC, Wong SC, Chuang VWM, So SYC, Chen JHK, Sridhar S, Yuen KY (2020) The role of community-wide wearing of face mask for control of coronavirus disease 2019 (COVID-19) epidemic due to SARS-CoV-2. J Infect 81(1):107-114
Das A, Garg R, Ojha B, Banerjee T (2020) Biomedical waste management: the challenge amidst COVID-19 pandemic. J Lab Physicians 12(2): 161

De-la-Torre GE, Aragaw TA (2021) What we need to know about PPE associated with the COVID-19 pandemic in the marine environment. Mar Pollut Bull 163:111879

Dharmaraj S, Ashokkumar V, Hariharan S, Manibharathi A, Show PL, Tung CC, Ngamcharussrivichai C (2021) The COVID-19 pandemic face mask waste: a blooming threat to the marine environment. Chemosphere 129601

Doan HN (2020) Medical face masks can be reused with microwave method: expert. https://vietnamnews.vn/society/654072/medic al-face-masks-can-be-reused-with-microwave-\%20methodexpert.html. Accessed 01 April 2021

Elkhebu A, Zainorabidin A, Asadi A, Bakar IH, Huat BB, Abdeldjouad L, Dheyab W (2019) Effect of incorporating multifilament polypropylene fibers into alkaline activated fly ash soil mixtures. Soils Founda 59(6):2144-2154

Eyo EU, Abbey SJ (2021) Machine learning regression and classification algorithms utilised for strength prediction of OPC/ by-product materials improved soils. Constr Build Mater 284:122817

Feng S, Shen C, Xia N, Song W, Fan M, Cowling BJ (2020) Rational use of face masks in the COVID-19 pandemic. Lancet Respir Med 8(5):434-436

Ferdosian I, Camões A (2017) Eco-efficient ultra-high performance concrete development by means of response surface methodology. Cem Concr Compos 84:146-156

Güllü H, Fedakar HI (2017) Response surface methodology for optimization of stabilizer dosage rates of marginal sand stabilized with sludge ash and fiber based on UCS performances. KSCE J Civ Eng 21(5):1717-1727

Gupta M, Gupta K, Gupta S (2020) The use of facemasks by the general population to prevent transmission of Covid 19 infection: a systematic review. medRxiv. https://doi.org/10.1101/2020.05.01. 20087064

Haghani M, Bliemer MC, Goerlandt F, Li J (2020) The scientific literature on Coronaviruses, COVID-19 and its associated safety-related research dimensions: a scientometric analysis and scoping review. Saf Sci 129:104806

Haleem A, Javaid M, Vaishya R (2020) Effects of COVID 19 pandemic in daily life. Curr Med Res Pract 10(2):78-79

Hamzavi IH, Lyons AB, Kohli I, Narla S, Parks-Miller A, Gelfand JM, Ozog DM (2020) Ultraviolet germicidal irradiation: possible method for respirator disinfection to facilitate reuse during the COVID-19 pandemic. J Am Acad Dermato 82(6):1511-1512

Hantoko D, Li X, Pariatamby A, Yoshikawa K, Horttanainen M, Yan M (2021) Challenges and practices on waste management and disposal during COVID-19 pandemic. J Environ Manage 286:112140

Ibn-Mohammed T, Mustapha KB, Godsell JM, Adamu Z, Babatunde KA, Akintade DD, Koh SCL (2020) A critical review of the impacts of COVID-19 on the global economy and ecosystems and opportunities for circular economy strategies. Resour Conserv Recycl 164:105169

Khalid U, Rehman Z (2018) Evaluation of compaction parameters of fine-grained soils using standard and modified efforts. International Journal of Geo-Engineering 9(1):1-17. https://doi.org/10. 1186/s40703-018-0083-1

Liao M, Liu H, Wang X, Hu X, Huang Y, Liu X, Lu JR (2021) A technical review of face mask wearing in preventing respiratory COVID-19 transmission. Curr Opin Colloid Interface Sci 52:101417

Lowe JJ, Paladino KD, Farke JD, Boulter K, Cawcutt K, Emodi M, Gibbs S, Hankins R, Hinkle L, Micheels T, Schwedhelm S, Vasa A, Wadman M,Watson S, Rupp ME, (2020) N95filtering facemask respirator ultraviolet germicidal irradiation (UVGI) process 
for decontamination and reuse. Nebrasca Medicine. https://clean hospital.com/wp-content/uploads/2020/03/N-95-decon-process. pdf. Accessed 01 April 2021

Matuschek C, Moll F, Fangerau H, Fischer JC, Zänker K, van-Griensven M, Haussmann J (2020) Face masks: benefits and risks during the COVID-19 crisis. Eur J Med Res 25(1):1-8

Mazumder P, Akhil PM, Khwairakpam M, Mishra U, Kalamdhad AS (2021) Enhancement of soil physico-chemical properties post compost application: optimization using Response Surface Methodology comprehending central composite design. J Environ Manage 289:112461

Meyers C, Kass R, Goldenberg D, Milici J, Alam S, Robison R (2021) Ethanol and isopropanol inactivation of human coronavirus on hard surfaces. J Hosp Infect 107:45-49

Nzediegwu C, Chang SX (2020) Improper solid waste management increases potential for COVID-19 spread in developing countries. Resources, conservation, and recycling 161:104947

Phanikumar BR (2020) Silica fume stabilization of an expansive clay subgrade and the effect of silica fume-stabilised soil cushion on its CBR. Geomech Geoengin 15(1):64-77

Pinheiro C, Rios S, da-Fonseca AV, Fernández-Jiménez A, Cristelo N (2020) Application of the response surface method to optimize alkali activated cements based on low-reactivity ladle furnace slag. Constr Build Mater 264:120271

Rahman MM, Bodrud-Doza M, Griffiths MD, Mamun MA (2020) Biomedical waste amid COVID-19: perspectives from Bangladesh. Lancet Glob Health 8(10): 1262

Rehman ZU, Zhang G (2019) Shear coupling effect of monotonic and cyclic behavior of the interface between steel and gravel. Can Geotech J 56(6):876-884

Rehman Z, Luo F, Wang T, Zhang G (2020) Large-scale test study on the three-dimensional behavior of the gravel-concrete interface of a CFR dam. Int J Geomech 26(6):04020046

Rehman Z, Zhang G (2021) Cyclic behavior of gravel-steel interface under varying rotational shear paths. Can Geotech J 58(3):305-316

Saberian M, Li J, Kilmartin-Lynch S, Boroujeni M (2021) Repurposing of COVID-19 single-use face masks for pavements base/subbase. Sci Total Environ 769:145527

Sangkham S (2020) Face mask and medical waste disposal during the novel COVID-19 pandemic in Asia. Case Stud Chem Environ Eng 2:100052

Sarkodie SA, Owusu PA (2020) Impact of COVID-19 pandemic on waste management. Environ Dev Sustain 23(5):7951-7960

Sharma HB, Vanapalli KR, Cheela VS, Ranjan VP, Jaglan AK, Dubey B, Bhattacharya J (2020) Challenges, opportunities, and innovations for effective solid waste management during and post COVID-19 pandemic. Resour Conserv Recycl 162:105052

Shehzad A, Khan AH, Rehman ZU (2015) Characteristics of low plastic clay contaminated by industrial effluents. Int J Adv Struct Eng 4(3):138-147
Singh N, Tang Y, Zhang Z, Zheng C (2020) COVID-19 waste management: effective and successful measures in Wuhan. China. Resour Conserv Recycl 163:105071

Singh P, Dash HK, Samantaray S (2020b) Effect of silica fume on engineering properties of expansive soil. Mater Today Proc 33:5035-5040

Sousa V, Bogas JA (2021) Comparison of energy consumption and carbon emissions from clinker and recycled cement production. J Clean Prod 306:127277

Suman R, Javaid M, Haleem A, Vaishya R, Bahl S, Nandan D (2020) Sustainability of coronavirus on different surfaces. J Clin Exp Hepatol 10(4):386-390

Tiwari N, Satyam N, Singh K (2020) Effect of curing on micro-physical performance of polypropylene fiber reinforced and silica fume stabilized expansive soil under freezing thawing cycles. Sci Rep 10(1): $1-16$

Türköz M, Savaş H, Tasci G (2018) The effect of silica fume and lime on geotechnical properties of a clay soil showing both swelling and dispersive features. Arab J Geosci 11(23):1-14

ur Rehman Z, Khalid U (2021) Reuse of COVID-19 face mask for the amelioration of mechanical properties of fat clay: a novel solution to an emerging waste problem. Sci Total Environ 794:148746

ur Rehman Z, Zhang G (2021) Three-dimensional elasto-plastic damage model for gravelly soil-structure interface considering the shear coupling effect. Comput Geotech 129:103868. https://doi. org/10.1016/j.compgeo.2020.103868

Van-Fan Y, Jiang P, Hemzal M, Klemeš JJ (2021) An update of COVID-19 influence on waste management. Sci Total Environ $754: 142014$

Worby CJ, Chang HH (2020) Face mask use in the general population and optimal resource allocation during the COVID-19 pandemic. Nat Commun 11(1):1-9

Wu HL, Huang J, Zhang CJ, He Z, Ming WK (2020) Facemask shortage and the novel coronavirus disease (COVID-19) outbreak: reflections on public health measures. EClinicalMedicine 21:100329

Xu F, Wei H, Qian W, Chen X, Xu T, He Y, Wen G (2020) Experimental investigation on replacing cement by sintered limestone ash from the steelmaking industry for cement-stabilized soil: engineering performances and micro-scale analysis. Constr Build Mater 235:117425

Yilmaz YÜKSEL (2015) Compaction and strength characteristics of fly ash and fiber amended clayey soil. Eng Geol 188:168-177

Publisher's note Springer Nature remains neutral with regard to jurisdictional claims in published maps and institutional affiliations. 